\title{
The Effectiveness of a New Graduate Nurse Precepted Orientation Program on Retention
}

\author{
Rose M. Morton
}

Follow this and additional works at: https://researchrepository.wvu.edu/etd

\section{Recommended Citation}

Morton, Rose M., "The Effectiveness of a New Graduate Nurse Precepted Orientation Program on Retention" (2014). Graduate Theses, Dissertations, and Problem Reports. 6268.

https://researchrepository.wvu.edu/etd/6268

This Dissertation is protected by copyright and/or related rights. It has been brought to you by the The Research Repository @ WVU with permission from the rights-holder(s). You are free to use this Dissertation in any way that is permitted by the copyright and related rights legislation that applies to your use. For other uses you must obtain permission from the rights-holder(s) directly, unless additional rights are indicated by a Creative Commons license in the record and/ or on the work itself. This Dissertation has been accepted for inclusion in WVU Graduate Theses, Dissertations, and Problem Reports collection by an authorized administrator of The Research Repository @ WVU.

For more information, please contact researchrepository@mail.wvu.edu. 
The Effectiveness of a New Graduate Nurse Precepted Orientation Program on Retention

Rose M. Morton MSN, RN, NE-BC

\author{
Capstone Project submitted \\ to the School of Nursing \\ at West Virginia University \\ in partial fulfillment of the requirements for the degree of \\ Doctorate of Nursing Practice \\ Leadership Track
}
Kari Sand-Jecklin Ed.D., Chair
Patricia Joyce Maramba DNP
Rose Morgan MS, RN

Department of Health Sciences

\title{
Morgantown, WV
}

2014

Keywords: new graduate nurse orientation, intent to stay, preceptor, preceptorship, precepted orientation. 


\title{
Abstract \\ The Effectiveness of a New Graduate Nurse Precepted Orientation Program on Retention
}

\author{
Rose M. Morton MSN, RN, NE-BC
}

Background: A shortfall of 340,000 registered nurses (RNs) is projected by the year 2020. New graduate nurses often experience anxiety, apprehension and stress with their first job after graduation. Approximately $30 \%$ of new graduate nurses leave their first jobs within the first year of practice, and 57\% within the second year. Many facilities are relying on new graduate nurses to fill vacancies. Recently a focus has been placed on orientation programs to prevent newly hired nurses from resigning. Orientation plays a critical role in job satisfaction and retention of the new graduate nurse.

Objective: The aim of this capstone project is to evaluate the effectiveness of a precepted orientation program on new graduate nurse retention, intent to stay, and satisfaction with the orientation program during the first six months of employment in a southern West Virginia (WV) hospital.

Method: Using Transition Shock Theory as the conceptual framework, new graduate nurse satisfaction with the precepted orientation program and intent to stay in their new job were evaluated. New graduate nurse turnover rates were also measured after three months and six months in the precepted orientation program.

Sample: All new graduate nurses with less than one year of nursing experience hired at a small Community hospital in southern WV between May 2012 and Aug. $2013(\mathrm{n}=20)$.

Results and Conclusion: New graduate nurse turnover decreased with none of the NGNs leaving compared to ten percent previous to the precepted orientation program. NGNs were satisfied with data suggesting intent to stay on the Anticipated Turnover Scale (ATS).

Keywords: new graduate nurse orientation, intent to stay, preceptor, preceptorship, precepted orientation. 


\section{Table of Contents}

Background and Significance - Statement of the Problem $\ldots \ldots \ldots \ldots \ldots \ldots \ldots \ldots$

Theoretical Framework $\ldots \ldots \ldots \ldots \ldots \ldots \ldots \ldots \ldots \ldots \ldots \ldots \ldots \ldots \ldots \ldots$

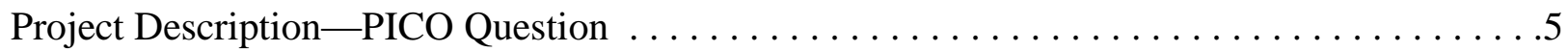

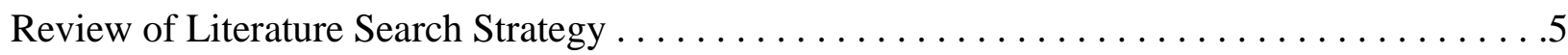

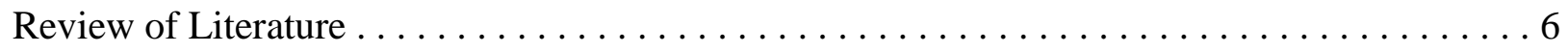

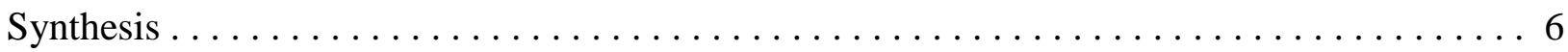

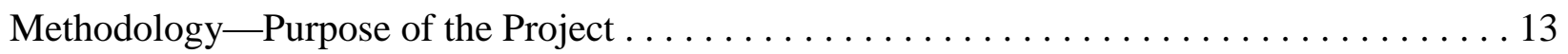

Relating the Organizations Strategic Plan to Practice Change Project . . . . . . . . . . . . . 14

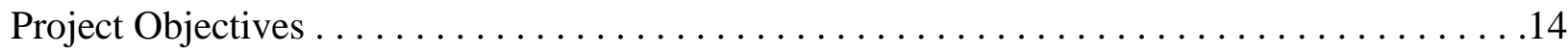

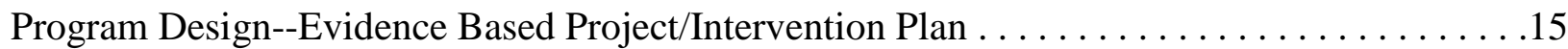

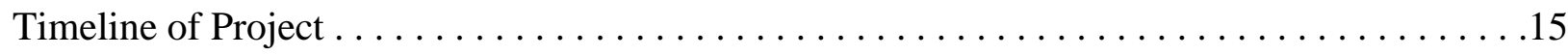

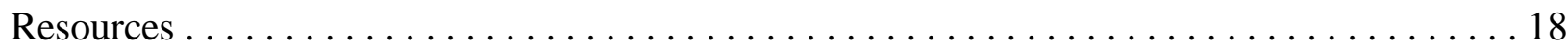

Measures and Analysis . . . . . . . . . . . . . . . . . . . . . . . .

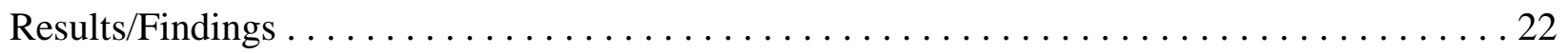

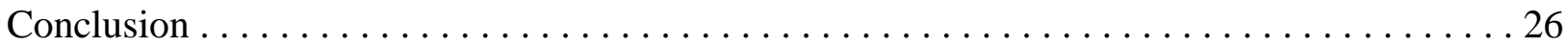

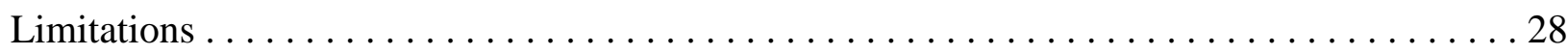

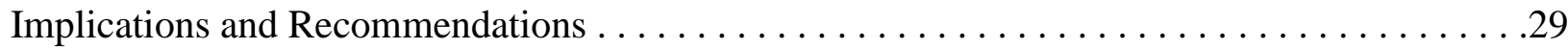

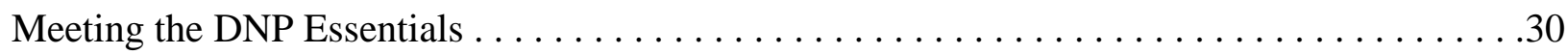

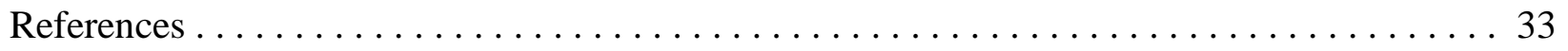

Table 1 Skills/Procedures NGNs Uncomfortable Performing Independently (Frequency of

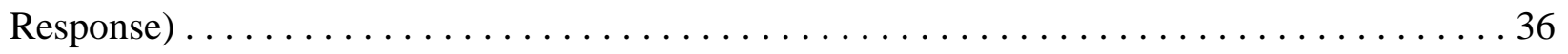


Table 2 Casey Fink Tool Responses (Response Scale of 1-4) . . . . . . . . . . . . . . 37

Table 3 NGN Satisfaction (Response Scale of $1-5) \ldots \ldots \ldots \ldots \ldots \ldots \ldots$

Table 4 Anticipated Turnover Scale Means (Response Scale of 1-5) . . . . . . . . . . . 40

Table 5 Preceptor/Preceptee Evaluation of Orientation (Response Scale of 1-5) . . . . . . . 41

Appendix I Weekly Orientation Performance Feedback Record . . . . . . . . . . . . . 42

Appendix II Letter of Request to Participate/Consent . . . . . . . . . . . . . . . . . .43

Appendix III Participant Demographic Questionnaire $\ldots \ldots \ldots \ldots \ldots \ldots \ldots \ldots \ldots \ldots \ldots$

Appendix IV Anticipated Turnover Scale $\ldots \ldots \ldots \ldots \ldots \ldots \ldots \ldots \ldots \ldots \ldots \ldots \ldots \ldots$

Appendix V Casey-Fink Graduate Nurse Experience Survey (revised) . . . . . . . . . . . . . 47

Appendix VI Preceptor Evaluation of Precepted Orientation Program . . . . . . . . . . . 59

Appendix VII Preceptee (NGN) Evaluation of Precepted Orientation Program . . . . . . . . 61

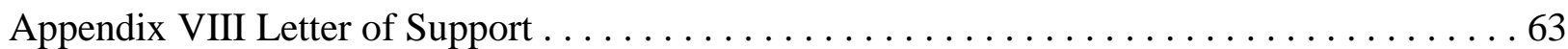




\section{The Effectiveness of a New Graduate Nurse Precepted Orientation Program on Retention}

This paper will describe the evaluation of a new graduate nurse (NGN) precepted orientation program that was implemented at a small, community hospital in southern WV. A theoretical framework of transition shock theory is also presented.

\section{Background and Significance of Proposed Intervention}

\section{Statement of the Problem}

The nursing shortage is a global problem (Lee, Tzeng, Lin \& Yeh, 2009). It is estimated that the nursing shortage will continue to increase with approximately 400,000 registered nurse vacancies in 2020 (Altier \& Krsek, 2006). Many facilities are relying on NGNs to fill these vacancies (Gardner et al., 2009). However, new graduate nurses often experience difficulty when transitioning into their first jobs, and a large percentage (approximately 30\%), leave employment in the first year of practice, with 57\% leaving by the second year (Salt, Cummings, \& Profetto-McGrath, 2008). The cost of recruitment and replacement of a registered nurse is estimated to be $\$ 40,000$ per employee (Gardner et al., 2009). Therefore, strategies to recruit and retain nurses are essential to meet the goals of adequate nurse staffing and provision of quality services to healthcare clients.

New nurses care for sicker patients in an increasingly complex healthcare setting, which increases their stress level. Increased stress levels and complexity of the work environment are risk factors for patient safety and practice errors. The increased percentage of turnover of new nurses in the first year of employment negatively affects patient outcomes (Beecroft, Kunzman, \& Krozek, 2001). Over time it has become evident that the inability of new nurses to transition into practice can have grave consequences. 
Focus has recently been placed on orientation programs to prevent new nurses from resigning their positions (Lee et al., 2009). Orientation plays a critical role in job satisfaction and retention of the NGN. It has been postulated that the first nursing orientation experience has influence on the new graduates' job satisfaction during their first 1 to 2 years of work experience (Scott, Engelke, \& Swanson, 2008). It "is a form of preventive medicine: investment of time and resources upfront to build a powerful foundation for a productive future" (Gardner et al., 2009, p. 9). NGNs need a supportive, nurturing environment where a mentor is readily available to provide guidance and structure to novice nurses transitioning into their new role (MurphyRozanski, 2008).

The Institute of Medicine Future of Nursing report (as cited in https://www.ncsbn.org/363.htm) called for the implementation and evaluation of Nurse Residency Programs. Transition to practice is extremely important to new nurses, patients, families, and employers. One significant component of a Nurse Residency Program is utilization of preceptors. Preceptorship programs have been used primarily in acute care settings. They have been shown to increase retention, decrease nurse turnover rates, and in turn decrease the need to rehire and orient additional nurses, decreasing the cost to the employer (Lee et al., 2009).

Preceptorships are intentional, individualized, formal agreements between individuals to engage in a time limited role apprenticeship. The preceptor-preceptee relationship links experienced nurses (preceptors) with NGNs (orientees or preceptees) to facilitate the new graduates' orientation and integration into their roles and responsibilities as a new professional nurse (Swihart, 2007). Preceptor relationships usually do not extend beyond the NGNs initial position and assigned work setting. If a preceptorship extends beyond the designed period of time it typically transitions to a mentorship (Swihart, 2007). 
In a study by Scott et al. (2008) 329 new graduate nurses in North Carolina were surveyed to determine the influence of personal factors such as age, marital status, race and gender on orientation, continuing education, and the influence of staff shortage on the satisfaction, intent to leave their job, and intent to leave the profession. The survey tool was developed by the NC Center for Nursing. New graduate nurses were defined as those that had graduated within the past six months to two years. Of the new graduates surveyed, $54.1 \%$ were dissatisfied with their current job and 55\% had already left their first job, with $70.8 \%$ still satisfied with nursing as a career. Fifty-eight point seven percent of respondents felt their orientation was not adequate. Turnover rate for those who felt their orientation had not met their needs was $60 \%$. New graduates that reported being satisfied with their job also reported being satisfied with their orientation. These same nurses were also more likely to be satisfied with nursing as a career. A strength of this study was that one of the most significant findings was the correlation between the role of orientation in the first job and job satisfaction and retention.

\section{Theoretical Framework}

This paper will discuss the theoretical framework chosen for the capstone project to implement a nurse precepted orientation program and how it relates to retaining NGNs in the workforce. NGNs often experience anxiety, apprehension and stress with their first job after graduation. A survey of NGNs revealed that they experienced high stress and difficulty transitioning from student to professional roles (Sandau \& Halm, 2010). Some of the root causes of these difficulties included lack of confidence in skill performance, lack of critical thinking or clinical knowledge, relationship issues with peers and preceptors, and struggles with dependence on others. New graduates also expressed frustration related to nurse to patient ratios, organizational skills, priority setting, and communication with physicians (Sandau \& Halm, 
2010). If NGNs do not receive appropriate training to assist in the transition to their professional role, they are at risk for leaving both their current job and the nursing profession. Because of many of the issues that NGNs face with transitioning into their new role, it was appropriate to utilize Transition Shock Theory as the framework for this capstone project.

Transition Shock theory builds on Kramer's theory of reality shock and the difficulty that new graduate nurses often have when transitioning into their first professional practice role. Although new graduates do anticipate changes, they are not prepared for the major contrast in the roles and responsibilities that they experience as a student and what they experience as a new graduate. Contrasts also exist between the relationships, knowledge, and performance expectations in these two roles (Duchscher, 2008).

Transition shock is embedded within the first stage of role transition when the new graduate moves from student nurse into the professional nurse role. There is a sharp contrast for the NGN in the relationships, roles, responsibilities, knowledge and performance expectations in the academic setting, and those of the professional practice role. Prior to the transition, NGNs anticipate a positive work environment, achievable roles and responsibilities, being recognized for the knowledge they had acquired, and for their commitment for caring for others (Duchscher, 2008). Transition shock usually occurs during the first four months of employment with the result being one of exhaustion and isolation for the NGNs. They experience disorientation, confusion and doubt-ridden chaos during this stage. Transition shock theory also postulates that the NGN will be confronted with emotional, physical, socio-developmental, sociocultural, and intellectual challenges (Dushscher, 2008). A precepted orientation program may help ease transition shock of NGNs because preceptors can support them in adaptation to the new role by 
developing relationships, supporting them in meeting role expectations, and making them feel like they are part of the team.

\section{Project Description}

\section{PICO Question}

For new graduate nurses employed by a rural community hospital, does a precepted orientation program impact retention in the first $\mathrm{RN}$ position compared to the current orientation program?

\section{Review of Literature and Synthesis}

\section{Search Strategy}

The search strategy used to identify the best evidence about orientation and retention of new graduate nurses included an in-depth search of National Guidelines Clearinghouse, Cochrane Library, PubMed, CINAHL, Academic Search Complete, Alt Health Watch, ERIC, Medline, PsychINFO, PsychARTICLES, Health Source: Nursing/Academic Ed., and Health Technology Assessments. Keywords used for the search were new graduate nurses, new graduate nurses and orientation, new graduate nurse orientation, graduate nurse orientation, graduate nurse retention, graduate nurse mentorship, graduate nurse intent to stay and new graduate nurse orientation and intent to stay. Initially, the search yielded a total of 7,334 hits, but when narrowed to keywords of graduate nurse orientation and retention the search yielded 244 hits. Additionally, the words preceptor and preceptorship were later added to the search. The search was limited to the years 2005 to 2011 initially and English language only. There was no limit placed on setting or geographic location. The type of evidence was restricted to systematic reviews, clinical practice guidelines, and research studies to provide for the highest available 
evidence. Ten initial studies were selected for inclusion with two later being excluded and snowballing being utilized to replace those two with higher level of evidence studies. Two of the studies were later excluded as well because one was deemed to be a weak study and the other was a qualitative study. Two more studies were added after the words preceptor and preceptorship were added to the search criteria. A total of ten articles of evidence met inclusion criteria: one systematic review (Salt et al., 2008), two quasi-experimental studies (Newhouse, Hoffman, \& Hairston, 2007, Lee et al., 2009), six descriptive comparative studies (Marcum \& West, 2004; Orsini, 2005; Altier \& Krsek, 2006; Friedman, Cooper, \& Click, 2011; Weng, Huang, Tsai, Chang, Lin, \& Lee, 2010; Beecroft, Kunzman, \& Krozek, 2001), and one descriptive correlational study (Scott et al. 2008).

\section{Review of Literature}

A critical appraisal was done for each of the ten documents using the appropriate tools. The Scottish Intercollegiate Guideline Network (SIGN) tool for Systematic Reviews \& MetaAnalyses was used for the systematic review (SR) by Salt et al. (2008). The Larrabee Literature Review Worksheet for Quantitative Research (Larrabee, 2009) was used for all other studies. All were individually appraised for internal validity, overall assessment of the study, and the description of the study. An evidence table was also created.

The SR manuscript indicated that a three to six month preceptor model is the best strategy for new graduate nurse retention, but also stated that implementing a retention strategy, regardless of the type or length, will result in positive retention outcomes (Salt et al, 2008). There were sixteen studies included in the SR: nine one-time experimental case design, one static group comparison, three one-group pretest-post test studies, and three non-randomized control trials (NRCTs). Some of the studies used previous retention rates or literature to compare their 
success or failures and all failed to show specific cause and effect of the implemented program and retention rates (Salt et al., 2008).

The SR met the defined criteria but was determined to be weak because the authors determined the studies included in the SR to be of weak designs. It also cited a limitation of only utilizing published studies which may have compromised the overall outcome of the review, since these studies tend to over report positive findings (Salt et al., 2008).

The quasi-experimental study by Newhouse et al. (2007) sought to determine whether an internship program, Social and Professional Reality Integration for Nurse Graduates (SPRING), improved new nurse graduate retention, sense of belonging, organizational commitment, and anticipated turnover. The study was conducted in an academic institution initially involving only two units, but over a 12 month period a total of seven departments participated. All newly hired nurses with less than one year of experience were invited to participate in SPRING. Those choosing not to participate were placed in the non-SPRING group. There were 277 SPRING group participants and 115 non-SPRING participants in the study. The SPRING program included an educational component, group exercises, mentoring by educators and preceptors, and individualized personal development plans for NGNs. In addition to standard unit orientation the SPRING participants attended 10 educational seminars during their first year of employment. There was a dedicated part-time SPRING nurse educator that made rounds to meet with the NGNs, preceptors, and unit managers regarding any problems, issues, or concerns that are often encountered during orientation and role transition to practice.

At six months, 237 SPRING participants continued employment and at 12 months 212 participants remained in their positions. Organizational commitment was measured using the Organizational Commitment Questionnaire. Sense of belonging was measured by the Modified 
Hagerty-Patusky Sense of Belonging Instrument, and anticipated turnover was measured by the Anticipated Turnover Scale. There were significant differences found between the groups in anticipated turnover rates. Control group nurses were more likely to consider leaving their job as opposed to 6-month SPRING nurses. There were no significant differences in sense of belonging psychologically. Strengths of the study were that there were significant differences between 12-month retention between the SPRING group and the comparison group. The study demonstrated a significant difference in retention between the SPRING group at 12 months as compared to the non-SPRING group (Newhouse et al., 2007).

A quasi-experimental study by Lee et al. (2009) investigated the impact of a preceptorship program on nurse turnover rate, turnover cost, quality of care and professional development. The preceptorship program included a nine-hour preceptor training course with a post-test for participants to qualify as a preceptor. Preceptors worked one-on-one for a period of three months, and monthly meetings with preceptors and NGNs were held to discuss any problems or issues. The meetings also helped to facilitate a supportive environment to assist both preceptors and NGNs to learn and grow. The study was conducted at Tri-Service General Hospital, an 1800 bed teaching medical center in Taipei, Taiwan. There were 34 new nurses and 24 preceptors participating in the study. Turnover rate was extracted from the databank of the study hospital and turnover cost was estimated from the employee's salary. After the preceptorship program, the turnover rate was $46.5 \%$ lower than in the previous year. The turnover cost savings was $\$ 186,102$ during the six-month study period. A strength of the study is the identification of significant cost savings related to the preceptorship program. A limitation of the study is that no statistics were utilized for turnover rate or retention other than percentages (Lee et al. 2009). 
The descriptive comparative study by Marcum \& West (2004) sought to increase retention rates through the use of a structured, progressive precepted orientation program. The study was conducted at an acute care hospital on a medical unit using two groups of graduate nurses for comparison. The preceptor program included training for the preceptors to reinforce goals of the unit, workflow, preceptor expectations, profile of new graduates, and the competency and performance evaluation process. The program also included 13 weeks of unit based training for the new graduates, followed by two and a half weeks of general hospital orientation. The nursing process and a Weekly Preceptor Evaluation Form were used to measure preceptor performance. RN competency was measured by the RN Competency Assessment. With the original system there was a turnover rate of $29 \%$ and $41 \%$ in two consecutive years. With the new system the turnover rate was $24 \%$, which was a sizable decrease from the previous year. A limitation of this study was that there were no other statistics to report for this study related to turnover rate or retention other than percentage.

A descriptive, comparative study by Orsini (2005) sought to determine if a structured nurse transition program utilizing a single dedicated preceptor with new graduate nurses would decrease nurse turnover. Specific selection criteria were utilized to select preceptors for the pilot program. Each week new graduate orientation goals were determined and then evaluated to determine if they had been met. A weekly evaluation form was used and the preceptor and the clinical coordinator tracked NGN progress each week. The pilot program only had three participants. The study was conducted at an inpatient orthopaedic department at a large community hospital in the southeastern U.S. with new graduate nurses. Employee satisfaction, cohesiveness, and nurse friendliness were measured by Employee Satisfaction Surveys. The program did decrease the nurse turnover rate. The turnover rate in 2001 was $22.8 \%$ and 1 year 
later, after implementing the transition program for new graduate nurses it dropped to $7.7 \%$. A limitation of this study was that no statistics were utilized; only percentages were reported and the sample size was very small.

Altier \& Krsek (2006) sought to evaluate the effect of participation in a 1-year residency program by graduate nurses on job satisfaction and retention during the first year of employment. The residency program consisted of a standardized curriculum which included research-based practice, patient safety, communication, leadership, and professional development. NGNs participated in general hospital orientation, preceptor guided clinical experiences, and also had access to a resident facilitator for discussion of issues or problems. This descriptive comparative study enrolled 316 new graduate nurses from six academic medical centers in the 1-year residency program. Job satisfaction was measured using the McCloskey-Mueller Satisfaction Survey. The program retained $87 \%$ of the new graduate residents at the end of the 1-year program, or 275 of the 316 participants. Approximately 10\% (31 of 316) left the employment for various reasons: five left due to illness, ten due to relocating, eleven for dissatisfaction, and five gave no reason. Satisfaction scores were computed as a sum. Total satisfaction scores may range from 31 to 155 with a standardized mean of 108.5 (low scores indicate low satisfaction). Two of ten measures demonstrated a statistically significant decrease in scores, praise and professional opportunities. The other eight showed non-significant, minimal change. Pre-test score range for praise was four to 20 with a mean of 15.69 ; post-test score range was five to 20 with a mean of 14.56. Pre-test score range for professional opportunities was seven to 20 with a mean of 13.27; post-test score range was four to 18 with a mean of 23.69. A limitation of this study was that only these two measurements demonstrated a statistically significant decrease in score. 
A descriptive comparative study of the impact of an internship program for new nurse graduate employees was conducted by Beecroft et al. (2001) on an acute care pediatric unit in an urban children's hospital. The study enrolled 50 new graduate nurses in the internship group and 28 in the control group. Nursing turnover was measured using the Anticipated Turnover Scale (ATS). On the ATS, at 6 months, there was a significant difference between the two groups, with the control group ATS scores reflecting a greater possibility of voluntary termination. The percentage of employees who actually left the facility within the 12 month period was calculated for the actual turnover statistics. The HR department indicated a turnover rate of $36 \%$ for the control group and a $14 \%$ turnover rate for the intern group. Data from the Healthcare Association of Southern California reported an average turnover rate of new graduate nurses with less than 12 months experience during the last three quarters of 2000 to be $46 \%$. Thus, study findings were favorable in comparison to the HASC data as well as with previous turnover data. A strength of this study is that it was able to identify this significant difference.

A retrospective descriptive study by Friedman et al. (2011) sought to determine the retention rate and costs associated with the employment of new graduate RNs before and after the initiation of a specialized, year-long, critical care orientation program. The year-long critical care orientation program consisted of three parts. The first part consisted of a core curriculum, professional seminars, and clinical simulations. The second part consisted of a one-on-one clinical experience with an experienced critical care RN. The third part consisted of the NGNs having their own clinical assignment with a nurse educator on site to respond to any questions, problems, or issues.

The specialized orientation program was implemented on critical care units of two tertiary hospitals in a multi-hospital health care system in Long Island, NY. There were 90 new 
graduate nurse participants. Basic descriptive statistics using measures of central tendency and dispersion were used to calculate the difference in retention for new graduate RNs pre and postinitiation of the orientation program. The annual retention rate for standard orientation in 2004 was 53.3\%, and for the Critical Care Fellowship Program in 2007, retention was 78.3\%. Advertising expenses in 2004 for standard orientation were $\$ 488,596$ and in 2007 for the Critical Care Fellowship Program were $\$ 166,095$ with a cost savings of $\$ 322,501$. Authors identified a potential savings estimate of $\$ 1,367,100$ annually.

Finally, Weng et al. (2010) examined the impact of mentoring on job satisfaction and organizational commitment of new nurses. Participants were 306 new nurses from three regional hospitals in Taiwan. The program length for the participants varied from at least two months but some participants had up to four months in length. Mentoring function scales were used to measure career development function, psychosocial support function, and role modeling function. The Minnesota Satisfaction Questionnaire was used to measure work satisfaction and the Organization Commitment Questionnaire was used to measure organizational commitment. Only the career development function and the role modeling function were found to be significantly and positively related to job satisfaction. The regression analysis for organizational commitment showed that sample source, nursing experience, mentor having prior mentoring experience, and frequency of interactions with the mentor had a significant influence on organizational commitment.

\section{Synthesis}

There was homogeneity across the studies in that consistent improvement in retention rates of new graduate nurses occurred when a NGN orientation utilizing a preceptorship or like program was implemented. Various types of orientation programs were utilized. Preceptor 
programs, internships, mentors, and residency programs were some of the orientation programs studied. Some orientation programs were three to six months in length, whereas others were one year residency type programs. Preceptor, internship, and residency programs may last six months to a year, depending on how designed. Nurse residency programs for NGNs are comprehensive, structured progressive programs with ongoing support, designed to increase graduate nurse independence and confidence. They are usually six to 12 months in length in order to provide crucial support that is needed during the most vulnerable time of role transition and the time of highest risk for nurses leaving the job and the nursing profession altogether. Nurse residency programs typically include peer support, promotion of critical thinking, use of research findings, and a competency-development framework such as Benner's novice to expert model (Washington Center for Nursing, 2008).

All of these types of orientation program have been found beneficial and contributed to increased retention and decreased turnover for new graduate nurses, although a "best practice" program that combines the best outcomes with the lowest cost has not yet been determined.

\section{Methodology}

\section{Purpose of the Project}

The purpose of this project was to provide a precepted orientation to NGNs to ease the impact of transition shock, and to evaluate its effectiveness by measuring NGNs satisfaction with the program, intent to remain in employment, and actual NGN retention/turnover rates. Previous orientation at Princeton Community Hospital $(\mathrm{PCH})$ did not include NGNs working with a preceptor; therefore a precepted orientation was a new type of orientation being provided. 


\section{Relating the Organizations Strategic Plan to Practice Change Project}

The mission of $\mathrm{PCH}$, where the project was completed, is to "lead in building a health care system that provides a broad range of health care services which improve the health status of individuals in a defined geographic region" (www.pchonline.org) and to "emphasize high quality, low cost and predictable outcomes" (www.pchonline.org). In order to achieve this organizational goal, sufficient and consistent nurse staffing is needed. PCH is a 267 bed acute care hospital in southern WV, employing a total of 171 RNs. The vacancy rate in April 2012 for RNs was $3.51 \%$ and $6.85 \%$ for LPNs. They estimate their cost to orient a NGN to be $\$ 25,000$ per nurse. The RN turnover rate for July 1, 2010 to June 30, 2011 was $6.65 \%$, and 5.06\% for July 1, 2011 to April 30, 2012. The NGN turnover rate for July 1, 2010 to June 30, 2011 was 10\%. One of the strategic initiatives for $\mathrm{PCH}$ for 2012 was to implement a precepted orientation program, making this project an excellent one to implement at the time it was begun. The goal of the project, implementation of a precepted orientation program, was to increase nursing retention, decreasing nursing turnover. There was a necessity of clear, concise communication to preceptors and NGNs to achieve this goal.

\section{Project Objectives}

The overall objective/outcome to be achieved/evaluated as part of this capstone project was to reduce transition shock and increase NGN retention after three and six months of employment through implementation of the precepted orientation program. Specifically: 
1. NGNs would perceive high levels of support, professional satisfaction, and communication, as measured with the Casey Fink New Graduate Nurse Experience Survey at both the three and six months post hire measures.

2. NGNs would maintain a high "intent to stay" in their position at $\mathrm{PCH}$ as measured with the Anticipated Turnover Scale between three and six months post hire.

3. NGNs and preceptors would be satisfied with the precepted orientation at the completion of the program, as evidenced by responses to the Preceptor Evaluation form and the Preceptee Evaluation form.

4. The NGN turnover rate would be decreased at the end of the capstone project compared to the previous NGN turnover rate of ten percent.

\section{Project Design}

\section{Evidence Based Project/Intervention Plan}

This capstone project, constructed as a descriptive, prospective design employed a multipronged intervention of introduction of preceptors and preceptorship to NGNs, implementation of a weekly formative evaluation process with documentation of the process via a standardized evaluation tool, and monthly meetings with preceptors and preceptees to identify progress and any further education needed related to the preceptor program. Monthly meetings also provided any needed support to both new graduates and preceptors and identified any other needed resources.

The major stakeholders were the preceptors and NGNs. Nursing and hospital administrators and Human Resources staff are other stakeholders as they are concerned with the need to recruit and retain nurses, and with the costs associated with nurse turnover. The nurse 
educator is a stakeholder as he participates in educational workshops and the initial component of nurse orientation.

The preceptor program was designed to have the preceptee work one-on-one with a preceptor on their assigned unit for a period of at least three months. Preceptees would have already undergone hospital orientation by the time they were assigned to a preceptor and began the preceptor program. During the first two weeks preceptees were with a preceptor they were to shadow the preceptor only. The progression to independent professional practice was planned to be slow so that the transition would be smooth and learning optimal. During week three the preceptee was to be assigned one or two patients with the preceptor. The weekly assignments could be adjusted based on how the preceptor believed the preceptee was progressing. Once new graduates reached the week eight point they would continue to care for six to eight patients if they had progressed satisfactorily to that point. If a NGN preceptee had not reached that point yet, the preceptor would continue to add patients as he/she believed the preceptee was ready to care for additional patients. The preceptor completed weekly evaluations for the preceptee to provide constructive feedback. The preceptor and preceptee scheduled a time at the end of each week for at least 15 minutes to discuss progress and complete evaluation forms. Evaluation forms were to be submitted to the unit manager each week and would be utilized when completing the preceptee's 90 day evaluation. The preceptors also checked off preceptees on the required skills using the skills checklist as they progressed through the three month preceptorship. NGNs were expected to satisfactorily accomplish all skills during the preceptorship orientation time frame.

Twenty-two preceptors were trained at the Preceptor Training Workshop held on June 6, 2012 which followed the Nurse Preceptor Program Builder: Tools for a Successful Preceptor 
Program by Diana Swihart (2007). The Preceptor Training Workshop was a 6 hour workshop to educate the experienced nurse about being an effective preceptor. It included roles and responsibilities, preceptee responsibilities, role transition, competencies, performance requirements for the preceptor and preceptee, feedback and communication, length of program, and progression from precepting to mentoring new graduates.

Interventions for the capstone project included supporting preceptors and preceptees through the orientation program and development and implementation of the weekly formative preceptee evaluation, as well as development of the form (Appendix I) used to document the weekly evaluative process. The form included questions for the preceptee to complete regarding their experience for the week and an area for their feedback regarding the preceptorship for that week. There were training sessions provided to both the preceptors and preceptees to educate them on how to conduct a formative evaluation and how to use the evaluation form. Another intervention was monthly meetings with the preceptors and preceptees to assess for any needed educational support or resources during the three month preceptorship program. The project leader was able to meet with only eight preceptee/preceptor pairs on a monthly basis, due to difficulty in communicating with the pairs, and the tendency for preceptees to have additional preceptors other than the one they were initially assigned. Six weeks after the end of the three month preceptorship, a meeting was held with preceptees to see how things were progressing since they finished working with their preceptor.

\section{Timeline of Project}

Submission to the IRB was in June 2012. An affiliation agreement already existed between PCH and WVU School of Nursing. Survey tools utilized were already developed. Selection of preceptors for the preceptee was completed by hospital staff. The preceptor 
workshop had already taken place during June 2012. The NGNs began working in mid-May 2012 and mid-May 2013 and had orientation to the facility and other policies and procedures prior to beginning work with their preceptor. Preceptors had been educated on the precepted orientation and were paired with a NGN to work for a period of three months. Initially, NGNs choosing to participate in the study (see informational letter/consent Appendix II) completed a demographic questionnaire (Appendix III). The Anticipated Turnover Scale (Appendix IV) and Casey Fink New Graduate Nurse Experience Survey (Appendix V) were administered at three months and six months post-employment. Preceptors and preceptees completed separate evaluations (Appendix VI \& VII) on the precepted orientation experience upon completion of the orientation program (end of three months). Comparison of scores on the tools was made after all data collection was completed. Data analysis was completed in May 2014.

\section{Resources}

PCH gave formal support in the form of a letter for the project (Appendix VIII). Many resources were needed to implement this capstone project of a precepted orientation program. Resources included people, classroom space, educational materials, survey tools, time, and money. Funding for all resources was provided by $\mathrm{PCH}$.

The initial cost was the purchase of program resources being used to implement The NGN Preceptor Program. The cost of the chosen program "Nurse Preceptor Program Builder: Tools for a Successful Preceptor Program” (Swihart, 2007) is \$130, which includes ten handbooks for preceptors. Additional handbooks could be purchased in bundles of ten for $\$ 60$. The total cost for the program and handbooks was $\$ 250$, allowing 30 preceptors to each have a handbook. Time for screening preceptors that were chosen by the unit managers was approximately $\$ 225$, anticipating that it would take one to one and a half hours to complete this 
task initially, since a limited number of preceptors were needed for the first group of NGNs and the same preceptors were utilized with the second group of preceptees.

Another cost was the salaries of the twenty-two preceptors that attended the workshop day (six hours) and the salary of the unit manager presenting the program. This amount was approximately \$1092. It also included my time as an Educator during the workshop day which is approximately $\$ 180$. The total cost for the workshop day was approximately $\$ 1272$. This is a lower cost than had initially been anticipated because the program did not require as many workshop days as was thought would be needed. The cost of paying NGNs working 40 hours per week with a preceptor for three months after their hospital orientation was estimated to be $\$ 13440$, since they were not carrying the usual patient care "load" during this timeframe. This figure can only be estimated because the new graduate nurses were being paid less until they passed the NCLEX-RN and each took and passed the NCLEX-RN at various times. The cost of paying the preceptors working with the preceptees during the three month precepted orientation was estimated at $\$ 249600$ based on 20 preceptors being paid an incentive pay of $\$ 1.50$ per hour to precept the preceptee.

Paper and copying of materials for the project was approximately $\$ 500$. This cost was for preceptor applications, demographic questionnaires, and copies of policies and procedures (P \& Ps). The survey tools did not incur a cost to use. There was an additional cost for time spent by preceptors to meet with, reflect, and discuss evaluations with the NGNs. This cost was approximately $\$ 2400$, based on fifteen minutes per week for the three month period which includes the cost for the preceptor and the preceptee. The total cost of the project was approximately $\$ 269,019$ although some of the cost would have been incurred anyway since the NGNs would not have had a full patient load for at least a few weeks after starting. 


\section{Measures and Analysis}

The Casey Fink Graduate Nurse Experience Survey was developed over several years. It was originally developed in 1999 and revised in 2002. It has been used to survey over 250 nurses in hospital settings in the Denver area and was further validated by over 1,000 graduate nurse residents participating in the University Health System Consortium/AACN Post Baccalaureate Residency program.

The Casey Fink tool consists of five sections with the first section relating to skills and procedures the new graduate nurse is uncomfortable performing independently. Section three relates to job satisfaction and sections four and five are either demographic in nature or are openended. The second section is made up of 24 questions in which the respondent answers using a 4-point balanced response format (strongly disagree to strongly agree) and an additional question where the respondent answers "yes" or "no" to a series of stressors. All of the items, with the exception of the stressor items address the respondents' professional comfort, expectations or supports. The stress item addresses the respondent's personal life.

All items were subjected to exploratory factor analysis during psychometric testing. Principal Axis Factoring was selected to decrease the likelihood of overestimating the explained variance and item factor loadings common with Principal Components analysis. In the analysis a 5-factor solution was found, accounting for $46 \%$ of the variation in total scores. The factors were labeled Support, Patient Safety, Stress, Communication/Leadership and Professional Satisfaction. Reliability estimates for the factors ranged from .71 to .90. Specific constitution of the factors follows: Support-- $\underline{\alpha}=.90$, Patient Safety-- $\underline{\alpha}=.79$, Stress-- $\underline{\alpha}=.71$, Communication/Leadership $\underline{\alpha}=.75$, and Professional Satisfaction-- $\underline{\alpha}=.83$. If the survey tool is 
scored by summing all of the items, including the stress items, the internal consistency estimates is $\underline{\alpha}=.89$. The authors speak to the validity of the tool, stating

Content validity has been established by review of expert nurse directors and educators in both academic and private hospital settings. The content of this tool is derived from substantial and comprehensive literature review. This instrument was identified as discriminating between nurses with varied amounts of experience during the first year of practice (Casey, Fink, Krugman, Propst, 2004).

The Anticipated Turnover Scale (ATS) was developed by Hinshaw and Atwood in 1978 to study turnover intention in nurses. It is a 12 item questionnaire that is self-administered using a Likert-scale from agree strongly to disagree strongly. The tool's items relate to an employee's anticipated length of time to leave and their certainty of leaving the job. A total score is obtained by calculating the sum of all items in the scale and dividing by the total number of items in the scale. Higher scores reflect greater intent to leave the current job. Responses with a mean over 3.5 are considered an indication for turnover intention. The construct validity for the ATS was estimated using principal component factor analysis. Findings identified two factors which accounted for $55 \%$ of the variance. The internal consistency reliability estimated with Cronbach's $\underline{\alpha}$ was.84. The ATS has been used frequently to measure turnover intention among nursing in various healthcare settings. A meta-analysis study was conducted by Barlow and Zangoro (2010) to determine the consistency of reliability estimates and evidence of construct validity of the ATS scores across nursing studies in the U.S. The overall mean weighted effect size of reliability from 12 studies was .89 , indicating excellent reliability and construct validity. A parallel preceptor and preceptee evaluation questionnaire form was developed by the project leader to be completed by each preceptor and preceptee at the end of the NGNs precepted 
orientation period (6 months). These parallel surveys were used for comparison of perceptions about the precepted orientation program. The first five parallel items on the instruments contained 5 point Likert-type response options, from "not at all well" to "extremely well". A Cronbach's alpha for the forced-choice Likert items on the preceptor and preceptee instruments was calculated. The alpha for the Preceptee Evaluation of Precepted Orientation program was .91, and for the Preceptor Evaluation of Precepted Orientation program the alpha was .76-both within reasonable range for a five item scale.

\section{Results/Findings}

Twenty new graduates employed by the hospital between May 2012 and August 2013 consented to participate in the project. Demographic data analysis indicated that 19 of the 20 NGNs were female. Forty-five percent were age $21(n=9), 20$ percent were age $22(n=4), 5$ percent were age $23(n=1), 10$ percent were age $24(n=2)$, with the remainder being ages 26,27 , $35, \& 42(n=4)$. The majority were Caucasian $(95 \%, n=19)$ with five percent Hispanic $(n=1)$. Nineteen of the NGNs participating graduated with an Associate of Science Degree in Nursing $(95 \%, \mathrm{n}=19)$ and one graduated with a Bachelor of Science Degree in Nursing (5\%). One of the participants also had a non-nursing degree in psychology. Graduation dates of the NGNs were as follows: May $2012(\mathrm{n}=5)$, May $2013(\mathrm{n}=10)$, June $2013(\mathrm{n}=4)$, and Aug. $2013(\mathrm{n}=1)$.

The new graduates listed the top three skills or procedures they were uncomfortable performing independently at three and six months. Some of the skills listed, such as, vent care/management/assisting with intubation/extubation, arterial/venous lines/swan ganz (wedging, management, calibration, and CVP, cardiac output) are considered intensive care unit (ICU) skills and many NGNs may not have encountered those particular skills during the precepted orientation. Some of the most frequently listed skills or procedures were Code/emergency 
response, arterial/venous lines/swan ganz (wedging, management, calibration, CVP, cardiac output), central line care (dressing change, blood draws, discontinuing), chest tube care, vent care/management/assisting with intubation/extubation, intravenous (IV) medication administration/pumps/PCAs, bladder catheter insertion/irrigation, blood product administration/transfusion, NG care/suctioning/placement, ECG/EKG/Telemetry monitoring and interpretation, trach care and unit specific care (see Table 1). Responses were fairly similar at both data collection points, although ventilator care was identified as an uncomfortable skill less often on the second data collection point.

NGN job satisfaction was evaluated by analysis of responses on the Casey Fink Tool which was administered at three and six months post hire. A paired t test was used to determine whether there were differences in responses between the two data collection points. Differences were calculated in subscale scores on the Casey Fink Tool as well. The goal was to determine new graduate nurses' satisfaction with work, their orientation experience, and their increase in confidence. Generally, new graduates responded positively to the questions. (see Table 2 for mean scores) Items that had a mean of less than 3 (out of a possible 4) on both the 3 and 6 month survey were: comfortable communicating with physicians, comfortable with dying patients, and efficient at organizing patient care needs. There was a significant increase in the comfort level of NGNs delegating to the nursing assistants from three to six months postemployment: $\mathrm{t}(\mathrm{df} 19)=2.52, \mathrm{p}=0.021)$. On the other hand, there was a nearly significant decrease in new graduate perception of manager provision of encouragement and feedback between the 3 month and 6 month data collection periods; $\mathrm{t}(\mathrm{df} 19)=2.03, \mathrm{p}=.057)$.

Thirty-five percent of participants responded that they experienced stress in their personal life both at three and six months. At three months the most frequently reported stressor by 
participants was child care issues. Living situation was the next most frequent stressor at 3 months, followed by finances and personal relationships.

At six months, participants reported child care issues and personal relationship issues as their main stressors followed by student loans and living situation. Less commonly reported stressors at 6 months were finances and job performance.

NGNs were fairly well satisfied with their salary, vacation time, benefits package, work hours, weekends off, amount of responsibility, opportunity for career advancement, amount of encouragement and feedback received, and opportunity to work straight days both at three and six months of employment. There were no significant differences in NGN responses to these questions between the 3 and 6 month data collection periods (see Table 3).

The Anticipated Turnover Scale data suggests that the preceptees were satisfied and had intent to stay in their current positions. There were no significant changes between three and six months from respondents on the survey tool (see Table 4).

The Preceptor/Preceptee Evaluation Tool was completed at the end of six months. Overall, both preceptors and preceptees were positive about the precepted orientation program (see Table 5). There was a significant difference in NGN and preceptor perception of how well orientation prepared them for independent practice, with preceptors being more positive than NGNs t $(\mathrm{df} 17)=-2.38, \mathrm{p}=.029$. Thirty-seven percent of preceptees and preceptors met on a weekly basis for discussion of issues, concerns, problems, and evaluation. Weekly was the most frequently reported meeting time followed by responses of "each shift", "daily" and "not often" by both preceptees and preceptors.

The major concerns or struggles noted by NGNs during the precepted orientation program were "adjusting to the real world of nursing", "applying what was learned in nursing 
school", "being able to handle the fast pace", "keeping up with the number of patients assigned on the floor", "lack of confidence", "no steady preceptor", "time management", "time management and medication administration", "clinical skills", and "transition from student to nurse". Some of the major concerns and struggles that preceptors noted of the NGNs were "lack of skills", "keeping up with specialty", “prioritization and time management”, "patient load”, "too many rules and regulations to remember", and "working on their own without someone directly supervising”.

Thirty-one percent of NGNs reported that they were often overwhelmed about transitioning to their full role as a nurse; however perception of preceptors was that NGNs were only overwhelmed $14 \%$ of the time. Only $11 \%$ of NGNs report being pulled out of the precepted orientation early; prior to three months.

According to the NGNs those things that worked well during the precepted orientation were having demonstration by preceptor, gradual transition to the role, having preceptor explanation of theory and then application, having preceptor readily available to answer questions, having the same preceptor, becoming familiar with the unit and staff, learning skills without being criticized, and having a preceptor for three months. These were individual comments made by the NGNs except for the comment regarding having the same preceptor which was made twice. NGNs were happy to have preceptors to work one-on-one with even though, at times they had more than one dedicated preceptor. They also reported having developed relationships with their preceptors that lasted beyond the precepted orientation. According to the preceptors some things that worked well were having additional pay for precepting, having the same preceptor, having time to work one-on-one, and reviewing from one shift to another. 
NGNs identified some things they believed did not work well during the precepted orientation, including not working on areas of needed improvement, having different preceptors, not being organized, and having too much paperwork to complete. These were individual comments; however the comment about having multiple preceptors was made by six NGNs, suggesting that having one dedicated preceptor is a relatively important component of the orientation program. Preceptors also cited some areas that did not work well such as the length of time for the precepted orientation, time frame being too short, NGNs having different preceptors, and pediatrics being closed.

No real data was collected from the weekly evaluation forms completed by the preceptees and preceptors. Discussion with the preceptees and preceptors regarding the forms is that, although they were completed much of the time, there was not enough time to have much meaningful discussion about them. Both preceptees and preceptors tend to agree that more time away from the unit to discuss what they had written on the forms would have been helpful.

There was $100 \%$ retention of the NGNs during the study period for both groups of NGNs. The NGNs were not permitted to transfer to another unit while on orientation but could transfer after their first six months, and some chose to do so after orientation but remained employed at PCH. Turnover of NGNs was $0 \%$ for 2012 and 2013 after the program was implemented. The retention rate for the year prior to implementation of the program was $90 \%$.

\section{Conclusion}

There is a global nursing shortage that is projected to continue well into the future. It is in the best interest of healthcare and nursing to determine the best ways to retain NGNs, the new entrants into the profession, and those with the longest potential work years. Assisting NGNs to make a smoother transition from nursing school into their new role of nurse in their first job has 
demonstrated to be beneficial in contributing to job satisfaction and retention of nurses.

Newhouse et al. (2007) concluded that a comprehensive orientation program for NGNs does increase retention among this group of nurses and also decreases their intent to leave the organization. The research has shown that a structured orientation assists with the transition, improves job satisfaction, increases retention and decreases turnover cost. The goal of this capstone project was to evaluate the effect of a nurse precepted orientation program on decreasing the turnover rate of NGNs at a small community hospital in southern WV.

The precepted orientation program did help ease transition shock of the NGNs, as preceptors supported them in adaptation to their new role by developing relationships and making them feel at ease when asking questions. The NGNs reported that their preceptors supported them in meeting role expectations and making them feel like they were part of the team. The NGNs were happy to have preceptors to work with one-on-one, although they identified that they preferred to have one dedicated preceptor rather than two or more. The NGNs also identified that they did maintain some type of relationship with their preceptor even after their precepted orientation had ended.

New graduates had relatively high job satisfaction at 3 months post employment, which stayed high at the 6 month data collection point. They also indicated comfort with a number of clinical skills. New grads did indicate some discomfort with technical skills, organizing their work, and interacting with both physicians and dying patients - comfort levels with these skills did not change significantly between data collection points. Perhaps 3 months is not long enough to expect a major change in these areas, as nurses may not have frequent enough opportunities to expand their skills and comfort significantly. However, they did indicate increased comfort in delegating tasks to nursing assistants_-very likely because they had ample 
opportunity to practice that skill. Finally, new graduate turnover was $0 \%$, in contrast to $10 \%$ for the year preceeding program implementation-representing a sizable cost savings. Overall, the program met the intended goals.

\section{Limitations}

Several limitations were encountered during the capstone project leading to further recommendations. One limitation was that there were a limited number of participants particularly in the first group $(n=5)$. The second cohort $(n=15)$ was needed to achieve the 20 participant sample size. The second cohort did not start until a year after the first group.

A second limitation is that the project leader (DNP student) had to make numerous visits to meet with preceptors and preceptees once the study was begun, because the NGNs were working on different units and on different shifts; it was not possible to meet with them as a group once they began. Communication was also difficult because most of the preceptees did not have email at the hospital and the project leader had to communicate indirectly with the preceptees through email with the Unit Managers.

Another limitation was that the project leader was an outsider not employed by the hospital where the study was conducted. Communication and contact with preceptors and NGNs may have been less troublesome if the project leader was employed at the hospital where the study was conducted. An additional limitation of the project was that, at times, the NGNs were placed with more than one preceptor rather than one dedicated preceptor as originally planned. Although necessary due to unforeseen circumstances such as illness of a preceptor or scheduled vacation time, it is best to have the preceptee remain with their assigned preceptor. The limited 
number of participants prevented comparison of findings according to demographics and/or clinical unit placement.

Several factors contribute to limitations in generalizability of this project findings. The population of NGNs were predominantly Associate Degree graduates, females, 20-21 years of age, and Caucasian. It is not possible to say whether the results of this project would have been similar, if the population was more heterogeneous.

\section{Implications and Recommendations}

This study supports the findings of other researchers in terms of demonstration that a structured precepted orientation for NGN's reduces transition shock, increases satisfaction with orientation, and decreases NGN turnover and costs related to replacement of new grads that leave employment. Recommendations resulting from this study are to keep NGNs with one dedicated preceptor, or two if the NGN is expected to rotate shifts, for the designated precepted orientation period and to have at least weekly meetings for discussion of concerns, issues, and evaluation. Another recommendation is to have the preceptor refer to the skills check-off to determine areas of weakness or skills that need more focus/practice during the precepted orientation, and to focus on these skills in the clinical setting as possibly in a simulated practice setting. As NGNs felt there was less support and encouragement from managers at the 6 month data collection point, it would be beneficial to discuss ongoing contact with and encouragement of the NGN employee by the unit manager. Additionally, since preceptors tended to believe NGNs were better prepared for independent practice than the NGNs felt themselves, it would make sense for managers to discuss perceptions of both preceptee and preceptor in relation to moving the NGN to an independent practice role, prior to concluding the orientation time. An 
ongoing, yet less formal mentor-type relationship is needed between the NGNs and the preceptor for continued connectedness.

There does seem to be a gap in knowledge concerning the length of time that is best for a precepted orientation program. Transition shock occurs for NGNs during the initial four months post-hire (Duchscher, 2009). Therefore, the recommendation from this project leader would be at least a six month precepted orientation allowing NGNs a smoother transition from NGN to professional nurse role. Further research is needed to determine the best type of orientation program and length of program for NGNs to smoothly transition into their new nurse role.

\section{Meeting the DNP Essentials}

Essential I, "Scientific Underpinnings for Practice” was met by integrating nursing science with knowledge from psychological theories and organizational science through basing the practice change project on the best evidence in the nursing literature, the transition shock theory and the organizational data that indicates that new graduate nurses have higher turnover rates than other newly employed nurses, costing the organization a sizable amount of money to replace.

Essential II, “Organizational and Systems Leadership for Quality Improvement and Systems Thinking", was met by developing and evaluating a new practice approach that met the needs of both the hospital organization and the new graduate nurses. The Project Leader assessed the financial impact of making the change to using a precepted orientation program for the NGNs and used advanced communication skills to implement and evaluate this program. The Project Leader also identified areas for continued improvement in the program; maintain one preceptor only for each new gad, nurse manager provision of long-term encouragement and 
support to the NGN, having a program coordinator who is employed at the institution and has access to NGN/preceptor schedules for meetings.

Essential III, “Clinical Scholarship and Analytical Methods for Evidence-Based Practice", was met by critically appraising the literature related to NGN turnover, transition shock theory, and NGN precepted orientation/residency. The project was based on the literature and on the needs of the institution. The Project Leader used appropriate research methods and analysis to determine the outcomes of the practice change, and to communicate these outcomes to stakeholders.

Essential IV, "Information Systems/Technology and Patient Care Technology for the Improvement and Transformation of Health Care", was met by using information systems to extract the needed data for determining NGN turnover rates and the costs of nurse turnover. The Project Leader developed an evaluation plan, gathered information/data, extracted data, and developed excel spreadsheets to import into SPSS for data analysis.

Essential V, "Health Care Policy for Advocacy in Health Care", was met by addressing the IOM report and suggestion of moving to nurse residency programs for newly employed NGNs. The Project Leader assisted the organization in implementing these recommendations. The Project Leader also educated nurse preceptors about this program. Essential VI, "Interprofessional Collaboration for Improving Patient and Population Health Outcomes", was met by employing good communication skills in interacting with nurse managers, preceptors, NGNs, and leading the team in implementing and analyzing the practice change to a precepted orientation program for NGNs.

Essential VII, “Clinical Prevention and Population Health for Improving the Nation's Health", was met by aggregating all information related to new graduate employment, 
satisfaction with orientation, and intent to remain in their positions, and the impact of these factors on providing care to patients in the acute care setting. Maintaining an adequate nursing workforce is critical to meeting the health needs of the population, and providing safe nursing care for the best patient outcomes.

Essential VIII, “Advanced Nursing Practice”, was met by demonstrating expert knowledge in relation to NGN entry into practice, and the factors impacting a successful entry and retention in the initial nursing position. The Project Leader developed a partnership with the institution to design and implement a practice change to improve the quality of orientation for NGNs, improve their confidence in practice, and maintain satisfaction in their RN positions. The Project Leader provided training and support for experienced nurses who were new to the preceptor role. The Project Leader demonstrated systems thinking, analytical skills, and professional judgment in both designing and analyzing the impact of the project that she implemented, considering outcomes for NGNs, preceptors, and the organization as a whole. 


\section{References}

Altier, M. \& Krsek, C. (2006). Effects of a 1-Year residency program on job satisfaction and retention of new graduate nurses. Journal for Nurses in Staff Development, 22(1), $70-77$.

Barlow, K.M. \& Zangoro, G. A. (2010). Meta-analysis of the reliability and validity of the Anticipated Turnover Scale across studies of registered nurses in the United States. Journal of Nursing Management, 18(7), 862-873.

Beecroft, P., Kunzman, L., \& Krozek, C. (2001). Outcomes of a one-year pilot program. Journal of Nursing Administration, 31(12), 575-582.

Casey K, Fink R, Krugman M, Propst J. (2004) The graduate nurse experience. Journal of Nursing Administration, 34 (6), 303-311.

Duchscher, J. (2009). Transition shock: the initial stage of role adaptation for newly graduated Registered Nurses. Journal of Advanced Nursing 65)5), 1103-1113.

Friedman, M., Cooper, A., Click, E., \& Fitzpatrick, J. (2011). Specialized new graduate RN Critical care orientation: Retention and financial impact. Nursing Economics, 29(1), $7-14$.

Gardner, C., Babin, A., Romero, K., Trull, K, \& Turpin, P. (2009) S.T.R.O.N.G.: Supporting the retention of new grads. Nursing Management, 9-12.

Hinshaw A.S. \& Atwood J.R. (1984). Anticipated turnover among nursing study: Final report. Tucson, AZ National Centre for Nursing Research and National Institute of Health, University of Arizona

Larrabee, J. H. (2009). Nurse to nurse: Evidence-based practice. New York: McGraw Hill. Lee, T., Tzeng., W, Lin, C. \& Yeh, M. (2009). Effects of a preceptorship programme on 
turnover rate, cost, quality and professional development. Journal of Clinical Nursing, $18,1217-1225$.

Marcum, E. \& West, R. (2004). Structured orientation for new graduates: A retention strategy. Journal for Nurses in Staff Development, 20(3), 118-124.

Murphy-Rozanski, M. (2008). A phenomenological investigation into mentors' helping behaviors in a nurse residency program: An emerging model (Doctoral Dissertation) Drexel University School of Education.

Newhouse, R., Hoffman, J. \& Hairston, D. (2007). Evaluating an innovative program to improve new nurse graduate socialization into the acute healthcare setting. Nursing Administration, 31(1), 50-60.

Orsini, C. (2005). A nurse transition program for othopaedics: Creating a new culture for nurturing graduate nurses. Orthopaedic Nursing, 24(4), 240-249.

Salt, J., Cummings, G., \& Profetto-McGrath, J. (2008). Increasing retention of new graduate nurses: A systematic review of interventions by healthcare organizations. Journal of Nursing Administration, 38(6), 287-296.

Sandau, K., \& Halm, M. (2010). Preceptor-based orientation programs: Effective nurses and organizations? American Journal of Critical Care, 19(2), 184-188.

Scott, E., Engelke, M., \& Swanson, M. (2008). New graduate nurse transitioning: Necessary or nice? Applied Nursing Research, 21, 75-83.

Swihart, D. (2007). Nurse Preceptor Program Builder: Tools for a Successful Preceptor Program (2 ${ }^{\text {nd }} E d$.), Marblehead, MA: HCPro, Inc.

Washington Center for Nursing (2008). A Master Plan for Nursing education in Washington State retrieved from www.wacenterfornursing.org May 23, 2012 
Weng, R., Huang, C., Tsai, W., Chang, L., Lin, S., \& Lee, M. (2010). Exploring the impact of mentoring functions on job satisfaction and organizational commitment of new staff nurses. BMC Health Services Research, 10(240).

www.pchonline.org retrieved 03/17/12 
Table 1

Skills/Procedures NGNs Uncomfortable Performing Independently (Frequency of Response)

\begin{tabular}{|l|c|c|}
\hline \multicolumn{1}{|c|}{ Skills/Procedures } & 3 mos & 6 mos \\
\hline Vent care/management/assisting with intubation/extubation & 7 & 4 \\
\hline Code/emergency response & 5 & 5 \\
\hline Central line care (dressing change, blood draws, discontinuing) & 5 & 5 \\
\hline $\begin{array}{l}\text { Arterial/venous lines/swan ganz (wedging, management, } \\
\text { Calibration, CVP, cardiac output) }\end{array}$ & 5 & 4 \\
\hline Chest tube care (placement, pleurovac) & 4 & 3 \\
\hline Intravenous (IV) starts & 3 & 2 \\
\hline ECG/EKG/Telemetry monitoring and interpretation & 2 & 1 \\
\hline NG care/suctioning/placement & 2 & 3 \\
\hline MD communication & 2 & 1 \\
\hline Trach care & 2 & 3 \\
\hline Blood product administration/transfusion & 1 & 2 \\
\hline Intravenous (IV) medication administration/pumps/PCAs & 1 & 0 \\
\hline Death/dying/end-of-life care & 1 & 2 \\
\hline Critical drips & 0 & 1 \\
\hline Bladder catheter insertion/irrigation & 1 & 2 \\
\hline Unit specific skills & 1 & \\
\hline
\end{tabular}


Table 2

Casey Fink Tool Responses (Response Scale of 1-4)

\begin{tabular}{|c|c|c|}
\hline Question & $\begin{array}{c}3 \text { month Mean } \\
\text { (SD) }\end{array}$ & $\begin{array}{c}6 \text { Month Mean } \\
\text { (SD) }\end{array}$ \\
\hline Feel confident communicating with physicians & $2.75(0.72)$ & $2.90(0.55)$ \\
\hline Comfortable with dying patients & $2.75(0.55)$ & $2.70(0.73)$ \\
\hline Comfortable delegating to NAs & $3.00(0.32)$ & $3.25(0.44)$ \\
\hline Ease asking help from other RNs & $3.65(0.59)$ & $3.50(0.83)$ \\
\hline $\begin{array}{l}\text { Not comfortable prioritizing pt care needs } \\
\text { (negatively worded) }\end{array}$ & $2.25(0.55)$ & $2.15(0.59)$ \\
\hline Preceptor provides encouragement \& feedback & $3.40(0.75)$ & $3.35(0.67)$ \\
\hline Staff available during new procedures \& situations & $3.65(0.59)$ & $3.45(0.69)$ \\
\hline $\begin{array}{l}\text { Overwhelmed by pt care responsibilities \& workload } \\
\text { (negatively worded item) }\end{array}$ & $2.30(0.66)$ & $2.10(0.64)$ \\
\hline Feel supported by nurses on unit & $3.60(0.68)$ & $3.45(0.69)$ \\
\hline Have opportunities to practice skills more than once & $3.45(0.69)$ & $3.45(0.69)$ \\
\hline Comfortable communicating with pts \& families & $3.45(0.51)$ & $3.45(0.61)$ \\
\hline Able to complete pt care assignments on time & $2.95(0.51)$ & $3.05(0.61)$ \\
\hline Feel expectations of me are real & $3.20(0.41)$ & $3.00(0.56)$ \\
\hline Prepared to complete by job responsibilities & $3.15(.49)$ & $3.10(.45)$ \\
\hline $\begin{array}{l}\text { Comfortable making suggestions/changes to nursing plan } \\
\text { of care }\end{array}$ & $3.00(.73)$ & $3.05(.51)$ \\
\hline Efficient organizing pt care needs & $2.00(0.65)$ & $2.15(0.59)$ \\
\hline $\begin{array}{l}\text { Unsafe due to lack of knowledge \& experience } \\
\text { (negatively worded item) }\end{array}$ & $2.20(0.77)$ & $2.30(.87)$ \\
\hline Positive role models observing me on unit & $3.50(0.69)$ & $3.45(0.61)$ \\
\hline Preceptor helps develop my confidence & $3.35(0.67)$ & $3.30(0.73)$ \\
\hline Supported by my family and friends & $3.50(0.61)$ & $3.45(0.61)$ \\
\hline
\end{tabular}




\begin{tabular}{|l|c|c|}
\hline \multicolumn{1}{|c|}{ Question } & $\begin{array}{c}3 \text { month Mean } \\
(\mathrm{SD})\end{array}$ & $\begin{array}{c}\text { 6 Month Mean } \\
(\mathrm{SD})\end{array}$ \\
\hline Satisfied with chosen nursing specialty & $3.40(0.50)$ & $3.40(0.68)$ \\
\hline Work is exciting and challenging & $3.45(0.51)$ & $3.40(0.50)$ \\
\hline Manager provides encouragement \& feedback & $3.50(0.51)$ & $3.10(0.72)$ \\
\hline Experiencing stress in personal life & $2.40(0.88)$ & $2.20(0.95)$ \\
\hline
\end{tabular}


Table 3

NGN Satisfaction (Response Scale of 1-5)

\begin{tabular}{|l|l|l|}
\hline Statement & $\begin{array}{l}3 \text { month Mean } \\
\text { (SD) }\end{array}$ & $\begin{array}{l}\text { 6 Month Mean } \\
\text { (SD) }\end{array}$ \\
\hline Satisfied with salary & $3.40(1.10)$ & $3.70(0.80)$ \\
\hline Satisfied with vacation & $3.95(0.76)$ & $3.70(0.81)$ \\
\hline Satisfied with benefits package & $4.00(0.65)$ & $3.75(0.64)$ \\
\hline Satisfied with work hours & $4.10(1.21)$ & $4.20(0.83)$ \\
\hline Satisfied with weekends off & $3.95(1.15)$ & $3.95(0.98)$ \\
\hline Satisfied with amount of responsibility & $3.95(0.69)$ & $3.95(0.69)$ \\
\hline Satisfied opportunities career advancement & $3.85(0.67)$ & $3.60(0.82)$ \\
\hline Satisfied amount manager encouragement \& feedback & $4.20(0.62)$ & $3.75(0.79)$ \\
\hline Satisfied opportunity to work straight days & $3.50(1.10)$ & $3.35(0.75)$ \\
\hline
\end{tabular}


Table 4

Anticipated Turnover Scale Means (Response Scale of 1-5)

\begin{tabular}{|l|l|l|}
\hline Statements & \multicolumn{1}{|c|}{$\begin{array}{c}\text { month Mean } \\
(\mathrm{SD})\end{array}$} & \multicolumn{1}{|c|}{$\begin{array}{c}\text { (SD) } \\
\text { (SD })\end{array}$} \\
\hline Plan to stay in position awhile & $4.60(0.63)$ & $4.67(0.62)$ \\
\hline $\begin{array}{l}\text { Quite sure I will leave position in } \\
\text { foreseeable future }\end{array}$ & $1.40(0.63)$ & $1.47(0.16)$ \\
\hline $\begin{array}{l}\text { Deciding to stay or leave my position is not } \\
\text { critical issue for meat this point in time }\end{array}$ & $3.53(1.24)$ & $3.40(1.30)$ \\
\hline $\begin{array}{l}\text { I know whether or not I'll be leaving this } \\
\text { Organization within a short time }\end{array}$ & $2.80(1.15)$ & $2.53(1.64)$ \\
\hline $\begin{array}{l}\text { If I got another job offer tomorrow, I would } \\
\text { give it serious consideration }\end{array}$ & $2.07(1.22)$ & $2.00(1.00)$ \\
\hline $\begin{array}{l}\text { I have no intentions of leaving my present } \\
\text { position }\end{array}$ & $4.20(1.26)$ & $4.20(1.21)$ \\
\hline $\begin{array}{l}\text { I have been in my position about as long as } \\
\text { I want to }\end{array}$ & $1.73(1.03)$ & $1.80(1.15)$ \\
\hline I am certain I will be staying here awhile & $4.27(1.16$ & $4.20(1.15)$ \\
\hline $\begin{array}{l}\text { I don't have any specific idea how much } \\
\text { longer I will stay }\end{array}$ & $2.40(1.30)$ & $2.67(1.23)$ \\
\hline I plan to hang on to this job awhile & $4.27(1.10)$ & $4.460(0.63)$ \\
\hline $\begin{array}{l}\text { There are big doubts in my mind as to whether } \\
\text { or not I will really stay in this organization }\end{array}$ & $1.87(1.13)$ & $1.60(0.83)$ \\
\hline I plan to leave this position shortly & $1.33(0.62)$ & $1.47(0.64)$ \\
\hline
\end{tabular}




\section{Table 5}

Preceptor/Preceptee Evaluation of Orientation (Response Scale of 1-5)

\begin{tabular}{|l|l|l|}
\hline Question & Preceptee Mean score & $\begin{array}{l}\text { Preceptor Mean } \\
\text { Score }\end{array}$ \\
\hline How well preceptor was prepared for role & 4.26 & 3.94 \\
\hline How well preceptor fulfilled role & 4.16 & 4.11 \\
\hline How well prepared for independent practice & 3.74 & 4.00 \\
\hline $\begin{array}{l}\text { How well did orientation prepare NGN for } \\
\text { roles \&Responsibilities on the unit }\end{array}$ & 4.00 & 4.00 \\
\hline $\begin{array}{l}\text { Orientation helped NGN feel like a team } \\
\text { member }\end{array}$ & 4.00 & 3.89 \\
\hline
\end{tabular}




\section{Appendix I}

\section{Weekly Orientation Performance Feedback Record}

Name:

Position:

Unit:

Date of employment:

Department:

Strengths:

Equipment/procedures demonstrated:

Areas needing experience and/or development:

Action plan:

What was most helpful this week to me as a preceptee:

What do I feel as a preceptee that I need to focus on more to make the transition to RN role?

Preceptee signature:

Date:

Preceptor signature:

Date: 


\section{Appendix II}

Dear Participant:

This letter is a request for you to take part in an evaluation of a precepted orientation program. The project is being conducted by Rose M. Morton MSN, RN, NE-BC as part of a Doctorate in Nursing Practice (DNP) degree at West Virginia University School of Nursing. Your participation in this project is greatly appreciated and will hopefully add to the adoption of preceptor program by other facilities. Your time and commitment will include completing a demographic questionnaire and two survey tools which will take approximately 45 minutes to complete. You will need to complete the survey tools after working 3 months with Youri préceptorat and again after 6 months of employment. You will also be asked to complete an evaluation of the precepted orientation program at the end of 3 months working with your preceptor.

Your involvement in this project will be kept as confidential as possible. All data will be reported in aggregate. I will not ask any information that could lead back to your identity as a participant. Your participation is completely voluntary. Your standing at Princeton Community Hospital will not be affected if you decide either not to particpate or to withdraw. West Virginia Universitys Institutional Review Board's acknowledgement of this project will be on file with the West Virginia University Research Corporation, 886 Chestnut Ridge Road, PO Box 6845, WVU, Morgantown, WV 26506. 
I hope that you will participate in this research project as it could be beneficial in assisting with transition and retention of new graduate nurses in the workforce.

Thank you very much for your time. Should you have any questions about this letter or the evaluation project, please feel free to contact me at rmorton3@mix.wvu.edu or my Capstone Project Chair, Dr. Kari Sand-Jacklyn at ksandjecklin@hsc.wvu.edu.

Thank you again for your time and consideration in helping with this important project.

Sincerely,

Rose M. Morton MSN, RN, NE-BC 


\section{Appendix III}

\section{Participant Demographic Questionnaire}

Gender: _ $\quad$ Male __ Female

Marital Status: ___ Married ___ Divorced ___ Single

Age:

$20-30$

$31---40$

$41---50$

$51---60$

$61---70$

Educational

Degree: __ ADN _ _ BSN __ Diploma __ MSN

Nationality: ___ Caucasian ___ Asian __ Indian __ African-American

Hispanic __ Other (Specify) 
Appendix IV

\section{Anticipated Turnover Scale}

INDICATE the DEGREE of your DISAGREEMENT or AGREEMENT with each statement by checking the appropriate box.

1.I plan to stay in my position awhile.......................

2. I am quite sure I will leave my position in the foreseeable future.
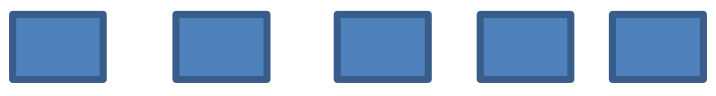

3. Deciding to stay or leave my position is not a critical issue for me at this point in time
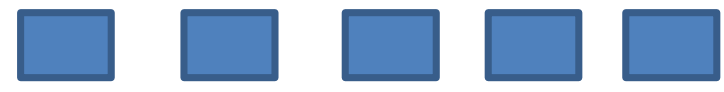

4. I know whether or not I'll be leaving this organization with a short time.
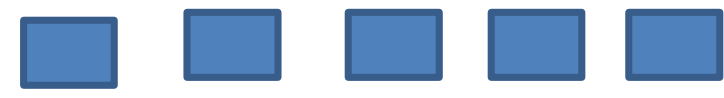

5. If I got another job offer tomorrow, I would give it serious consideration
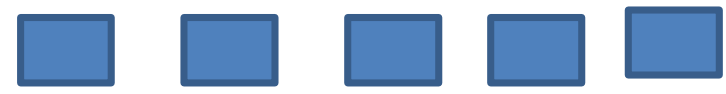

6. I have no intentions of leaving my present position
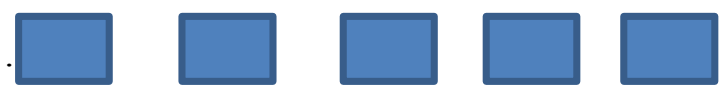

7. I have been in my position about as long as I want to......
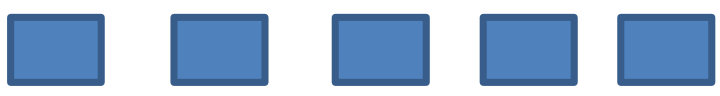

8. I am certain I will be staying here awhile
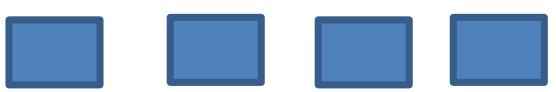

9. I don't have any specific idea how much longer I will stay
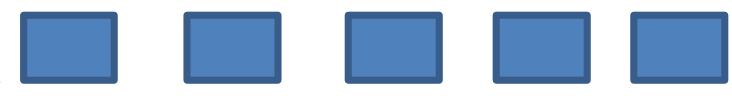

10. I plan to hang on to this job awhile
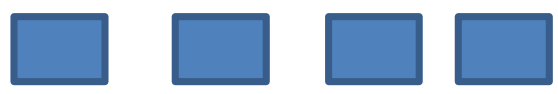

11. There are big doubts in my mind as to whether or not I will really stay in this organization.
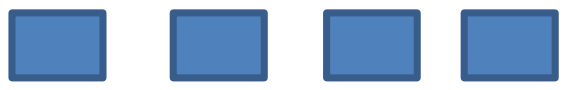

12. I plan to leave this position shortly
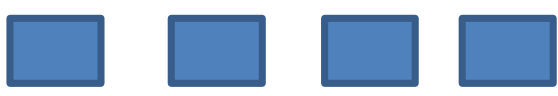


\section{Appendix V \\ Casey-Fink Graduate Nurse Experience Survey (revised) \\ (C) 2006 University of Colorado Hospital. All rights reserved.}

I. List the top three skills/procedures you are uncomfortable performing independently at

this time? (please select from the drop down list) list is at the end of this document.

1.

2.

3.

4. I I am independent in all skills

II. Please answer each of the following questions by placing a mark inside the circles:

STRONGLY

DISAGREE
DISAGREE

AGREE

STRONGLY

AGREE
1. I feel confident communicating with physicians.

2. I am comfortable knowing what to do for a dying patient. $\bigcirc$

$\bigcirc$

(1)

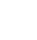


3. I feel comfortable delegating tasks to the Nursing Assistant.

4. I feel at ease asking for help from other RNs on the unit.

5. I am having difficulty prioritizing patient care needs.

6. I feel my preceptor provides encouragement and feedback about my work.

○

O

O

O

7. I feel staff is available to me during new situations and procedures.

O

O $\quad 0$

O

8. I feel overwhelmed by my patient care responsibilities and workload.

9. I feel supported by the nurses on my unit.

$\bigcirc$

$\bigcirc$

○

$\bigcirc$

10. I have opportunities to practice skills and procedures more than once.

O

$\bigcirc$

$\mathrm{O}$ 
11. I feel comfortable communicating with patients and their families.

○

$\bigcirc$

$\bigcirc$

O

12. I am able to complete my patient care assignment

○

$\bigcirc$

O

O on time.

13. I feel the expectations of me in this job are

$\mathrm{O}$

○

○ realistic.

14. I feel prepared to complete my job $\bigcirc$

O

O

$\bigcirc$ responsibilities.

15. I feel comfortable making suggestions for

○

$\bigcirc$

$\bigcirc$

$\bigcirc$ changes to the nursing plan of care.

16. I am having difficulty organizing patient care O needs.

17. I feel I may harm a patient due to my lack of $\bigcirc$ O O knowledge and experience. 
18. There are positive role models for me to observe

$\mathrm{O}$

O

○

O on my unit.

19. My preceptor is helping me to develop

O

$\bigcirc$

○

○ confidence in my practice.

20. I am supported by my family/friends.

○

$\bigcirc$

O

O

21. I am satisfied with my chosen nursing specialty.

○

$\bigcirc$

○

$\bigcirc$

22. I feel my work is exciting and challenging.

O

$\bigcirc$

$\bigcirc$

○

23. I feel my manager provides encouragement and

O

$\bigcirc$

$\bigcirc$

$\bigcirc$ feedback about my work.

24. I am experiencing stress in my personal life.

O

○

O

○ 
25. If you chose agree or strongly agree, to \#24, please indicate what is causing your stress. (You may circle more than once choice.)
a. NCLEX
b. Finances
c. Child care
d. Living situation
e. Personal relationships
f. Job performance
g. Graduate school

\section{How satisfied are you with the following aspects of your job:}

\begin{tabular}{ccccc}
\multirow{2}{*}{ VERY } & MODERATELY & SATISFIED & MODERATELY & VERY \\
DISSATISFIED & DISSATISFIED & NOR & SATISFIED & SATISFIED \\
& & DISSATISFIED & & \\
& & &
\end{tabular}

\section{Salary}

Vacation

Benefits package

Hours that you work

Weekends off per month

Your amount of responsibility 
Opportunities for career advancement

Amount of encouragement and feedback

Opportunity to work straight days

\section{Transition (please circle any or all that apply)}

1. What difficulties, if any, are you currently experiencing with the transition from the "student" role to the "RN" role?

a. role expectations (e.g. autonomy, more responsibility, being a preceptor or in charge)

b. lack of confidence (e.g. MD/PT communication skills, delegation, knowledge deficit, critical thinking)

c. workload (e.g. organizing, prioritizing, feeling overwhelmed, ratios, patient acuity)

d. fears (e.g. patient safety)

e. orientation issues (e.g. unit familiarization, learning technology, relationship with multiple preceptors, information overload)

2. What could be done to help you feel more supported or integrated into the unit?

a. improved orientation (e.g. preceptor support and consistency, orientation extension, unit specific skills practice)

b. increased support (e.g. manager, RN, and educator feedback and support, mentorship) 
c. unit socialization (e.g. being introduced to staff and MDs, opportunities for staff socialization)

d. improved work environment (e.g. gradual ratio changes, more assistance from unlicensed personnel, involvement in schedule and committee work)

\section{What aspects of your work environment are most satisfying?}

a. peer support (e.g. belonging, team approach, helpful and friendly staff)

b. patients and families (e.g. making a difference, positive feedback, patient satisfaction, patient interaction)

c. ongoing learning (e.g. preceptors, unit role models, mentorship)

d. professional nursing role (e.g. challenge, benefits, fast pace, critical thinking, empowerment)

e. positive work environment (e.g. good ratios, available resources, great facility, up-todate technology)

\section{What aspects of your work environment are least satisfying?}

a. nursing work environment (e.g. unrealistic ratios, tough schedule, futility of care)

b. system (e.g. outdated facilities and equipment, small workspace, charting, paperwork)

c. interpersonal relationships (e.g.gossip, lack of recognition, lack of teamwork, politics)

d. orientation (inconsistent preceptors, lack of feedback)

5. Please share any comments or concerns you have about your residency program: 
V. Demographics: Circle the response that represents the most accurate description of your individual professional profile.

1. Age: _ years

\section{Gender:}
a. Female
b. Male

\section{Ethnicity:}
a. Caucasian (white)
b. Black
c. Hispanic
d. Asian
e. Other
f. I do not wish to include this information

\section{Area of specialty:}

a. Adult Medical/Surgical 
b. Adult Critical Care

c. OB/Post Partum

d. NICU

e. Pediatrics

f. Emergency Department

g. Oncology

h. Transplant

i. Rehabilitation

j. OR/PACU

k. Psychiatry

1. Ambulatory Clinic

m. Other:

5. School of Nursing Attended (name, city, state located):

6. Date of Graduation:

7. Degree Received:

$\mathrm{AD}$ :

Diploma:

BSN:

ND:

8. Other Non-Nursing Degree (if applicable):

9. Date of Hire (as a Graduate Nurse): 
10. What previous health care work experience have you had:
a. Volunteer
b. Nursing Assistant
c. Medical Assistant
d. Unit Secretary
e. EMT
f. Student Externship
g. Other (please specify):

\section{Have you functioned as a charge nurse?}
a. Yes
b. No

12. Have you functioned as a preceptor?
a. Yes
b. No

\section{What is your scheduled work pattern?}
a. Straight days
b. Straight evenings
c. Straight nights
d. Rotating days/evenings 
e. Rotating days/nights

f. Other (please specify):

14. How long was your unit orientation?
a. Still ongoing
b. $\leq 8$ weeks
c. 9-12 weeks
d. $13-16$ weeks
e. 17 - 23 weeks
f. $\geq 24$ weeks

15. How many primary preceptors have you had during your orientation? number of preceptors

16. Today's date:

\section{Drop down list of skills}

Arterial/venous lines/swan ganz (wedging, management, calibration, CVP, cardiac output) Assessment skills

Bladder catheter insertion/irrigation

Blood draw/venipuncture

Blood product administration/transfusion 
Central line care (dressing change, blood draws, discontinuing)

Charting/documentation

Chest tube care (placement, pleurovac)

Code/Emergency Response

Death/Dying/End-of-Life Care

Dobhoff/NG care/suctioning/placement

ECG/EKG/Telemetry monitoring and interpretation

Intravenous (IV) medication administration/pumps/PCAs

Intravenous (IV) starts

Medication administration

MD communication

Patient/family communication and teaching

Prioritization/Time Management

Trach care

Vent care/management/assisting with intubation/extubation

Wound care/dressing change/wound vac

Unit specific skills 


\section{Appendix VI}

Preceptor Evaluation of Precepted Orientation Program

Not at all Somewhat Neutral Very Extremely

Well Well Well Well

$\begin{array}{lllll}1 & 2 & 3 & 4 & 5\end{array}$

1. How well did the preceptor training program

1

2

3

$4 \quad 5$

Prepare you for precepting the orientation of

New graduate nurse?

2. How well do you feel you fulfilled your role as 1

2

34

5

Precepting the orientation of a new graduate

Nurse?

3. How well prepared for independent

1

2

3

4

5

Practice as a nurse on your unit was the

New graduate at the conclusion of his/her

Orientation?

4. How much do you feel the precepted

1

2

3

4

5

Orientation helped to prepare the new

Graduate for independent practice as a

Nurse on your unit?

5. Did you meet regularly with your assigned

1

2

4

5 
New graduate to discuss progress to date

And identify orientation/practice goals

For upcoming shifts?

6. How do you feel the orientation progressed 1

2

3

4

To achieve the goal of independent practice

On the part of the new graduate?

Respond to the following with a short narrative answer:

1. What worked well with the unit precepted orientation of the new graduate nurse?

2. What didn't work as well with the precepted orientation?

3. What suggestions do you have for future precepted orientations of new graduate nurses? 


\section{Appendix VII}

Preceptee (NGN) Evaluation of Precepted Orientation Program

Not at all Somewhat Neutral Very Extremely

Well

$\begin{array}{lllll}1 & 2 & 3 & 4 & 5\end{array}$

1. How well prepared did you feel for the

1

2

34

5

Role of independent RN on the unit prior

To your precepted orientation program?

2. How well prepared do you feel for the role

1

2

3

4

5

Of independent RN on the unit at the

Conclusion of your precepted orientation

Program?

3. How well did the precepted orientation

1

2

3

4

5

Prepare you for the role of independent

Practice on your unit?

4. Did you meet regularly with your preceptor

1

2

34

5

To discuss your progress and identify

Orientation/practice goals for upcoming

Shifts? 
5. Did your orientation progress well, In order to achieve the desired goal Of independent practice?

Respond to the following with a short narrative answer:

1. What aspects of the precepted orientation worked well?

2. What aspects of the precepted orientation didn't work as well?

3. What suggestions do you have for future precepted orientations for new graduate nurses?

4. How many weeks did you have preceded unit orientation prior to being given your own patient assignment without a preceptor? 


\section{Appendix VIII}

Lisa Hardman, DNP

WVU School of Nursing

P. O. Box 9630

Morgantown, WV 26506

RE: Capstone Project for Rose Morton, DNP Candidate

Dear Dr. Hardman:

This letter is to support Rose Morton's Capstone project for her DNP degree. Nurse retention and satisfaction is a goal for all patient care facilities. Rose has suggested a project to develop a Preceptor Program for implementation with our new graduate nurses.

Princeton Community Hospital will be happy to provide space, scheduling, and other similar support necessary to accomplish this project. We will gladly support this project and feel that if shown to be effective, it could positively impact nurse retention and satisfaction at our facility.

Sincerely,

Rose Morgan, RN, BSN, MS

Vice President Patient Care Services

RM:Ic 